Article

\title{
Use of 3D Human Liver Organoids to Predict Drug-Induced Phospholipidosis
}

\author{
Ji-Young Lee ${ }^{1}$, Hyo-Jeong Han ${ }^{1}$, Sang-Joon Lee ${ }^{1}$, Eun-Ho Cho ${ }^{1}$, Han-Byul Lee ${ }^{1}$, \\ Ju-Hyung Seok ${ }^{1}$, Hee Seon Lim $^{1}$ and Woo-Chan Son ${ }^{2, *}$ \\ 1 Department of Medical Science, Asan Medical Institute of Convergence Science and Technology, \\ Asan Medical Center, University of Ulsan College of Medicine, Seoul 05505, Korea; \\ goodbye9068@hanmail.net (J.-Y.L.); hhyoj91@mail.ulsan.ac.kr (H.-J.H.); tkdwns516@gmail.com (S.-J.L.); \\ jhonho0724@gmail.com (E.-H.C.); onestar0620@naver.com (H.-B.L.); sjh4409@gmail.com (J.-H.S.); \\ lims3858@mail.ulsan.ac.kr (H.S.L.) \\ 2 Department of Pathology, University of Ulsan College of Medicine, Asan Medical Center, Seoul 05505, Korea \\ * Correspondence: wcson@amc.seoul.kr; Tel.: +82-2-3010-4051
}

Received: 10 March 2020; Accepted: 21 April 2020; Published: 23 April 2020

\begin{abstract}
Drug-induced phospholipidosis (PL) is a storage disorder caused by the formation of phospholipid-drug complexes in lysosomes. Because of the diversity of PL between species, human cell-based assays have been used to predict drug-induced PL in humans. We established three-dimensional (3D) human liver organoids as described previously and investigated their liver characteristics through multiple analyses. Drug-induced PL was initiated in these organoids and in monolayer HepG2 cultures, and cellular changes were systemically examined. Organoids that underwent differentiation showed characteristics of hepatocytes rather than HepG2 cells. The organoids also survived under PL-inducing drug conditions for $48 \mathrm{~h}$ and maintained a more stable albumin secretion level than the HepG2 cells. More cytoplasmic vacuoles were observed in organoids and HepG2 cells treated with more potent PL-induced drugs, but to a greater extent in organoids than in HepG2 cells. Lysosome-associated membrane protein 2, a marker of lysosome membranes, showed a stronger immunohistochemical signal in the organoids. PL-distinctive lamellar bodies were observed only in amiodarone-treated organoids by transmission electron microscopy. Human liver organoids are thus more sensitive to drug-induced PL and less affected by cytotoxicity than HepG2 cells. Since PL is a chronic condition, these results indicate that organoids better reflect metabolite-mediated hepatotoxicity in vivo and could be a valuable system for evaluating the phospholipidogenic effects of different compounds during drug development.
\end{abstract}

Keywords: 3D human liver organoids; drug-induced phospholipidosis; HepG2

\section{Introduction}

Drug-induced phospholipidosis (PL) is a phospholipid storage disorder caused by the formation of phospholipid-drug complexes in lysosomes, characterized as lamellar bodies by transmission electron microscopy [1]. Although the molecular mechanisms underlying drug-induced PL are still not fully understood, they are thought to be associated with the formation of an indigestible phospholipid-drug complex, the suppression of phospholipase activity, disrupting membrane fluidity [2], and an imbalance between the production and degradation of phospholipids [3,4]. Drug-induced PL is generally associated with amine-containing cationic amphiphilic drugs (CADs), which are protonated and captured in the lysosome's acidic environment, causing remarkable tissue accumulation of the drug [5].

The controversy continues over whether PL is a toxic or adaptive response. PL is generally considered to be an adaptive response rather than an adverse effect of a particular drug at the early 
stages [6]. PL can occur in target organs without organ-related toxicity or physiological consequences [7], however, there are cases in which PL is observed with target organ toxicity [8]. Due to the uncertainty of the toxicological outcome of PL, drug-induced PL discovered in preclinical studies can have a detrimental impact on pharmaceutical development and delay the process. Fatal genetic disorders such as Niemann-Pick disease and Tay-Sachs disease $[9,10]$ associated with PL have been described in humans, as has cell membrane damage leading to cell death. And other hepatic [11,12] cardiac [13,14], renal [15,16] pulmonary [17,18], eye [19], nervous [20], and skin [21] toxicities related to PL are known.

Although drug-induced PL can be detected preclinically using in vivo systems such as animal models [3,22-24], these types of studies are expensive, time-consuming, can raise ethical issues, and may not have specific toxicological relevance to humans. It has also been recommended that compounds that can lead to PL in humans should be identified and screened out in the early stages of drug discovery [25]. PL can be observed in any organ in the body, but the lung, liver, kidney, brain, spleen, and other lymphoid tissues are the most commonly involved sites [26]. To identify chemicals that provoke PL in humans, cell-based in vitro assays using various human liver cell types, such as HepG2 cells, HuH7 cells, and human primary hepatocytes have been investigated [27-29]. Immortalized cell lines derived from human hepatocellular carcinomas have the advantage of being easy to culture and quick growing. However, they do not represent a normal human liver because they retain the transformed characteristics of cancer cells. By comparison with cancer cell lines, primary human hepatocytes have characteristics that much more closely reflect a normal human liver, and also the individual patient. They are therefore more suitable for a toxicity test, but have the distinct disadvantage of losing viability very quickly in such testing, often within one week. Furthermore, the quantities of viable cells that can be obtained from primary tissues are always limited and hepatocytes themselves are fully differentiated and rarely proliferate in culture.

Organoids are a recently developed three-dimensional (3D) cell culture system for adult organs which enables the in vitro expansion of animal or human primary tissues [30]. Duct cells from an adult human liver form sphere-shape 3D structures in extracellular matrices. These so-called "organoids" can expand and proliferate through passaging in culture, unlike other primary cells, and they adopt hepatic characteristics when induced to differentiate by exposure to hepatocyte growth factors for 10-12 days. Human liver organoids can thus show properties of a normal liver or of the diseased condition of an individual patient. In addition, their unique 3D structures better reflect an in vivo environment compared to conventional two-dimensional (2D) cultures. Organoids are promising candidates for toxicity assessment, and several liver organoid models have been used to evaluate drug-induced hepatotoxicity by in vitro approach [31-33]. However, the reported toxicity studies with liver organoids are limited to assess cytotoxicity simply, and multiple applications of assays suitable for certain toxicologic phenomena such as phospholipidosis have not been reported yet.

In our current study, we established 3D human liver organoids in accordance with a method described previously [30]. To assess the feasibility of using adult human liver organoids to predict drug-induced PL, we compared the effects of drug-induced PL in these structures and in the HepG2 cell line. HepG2 is widely used $[27,29,34,35]$ for the in vitro screening for this PL condition and plenty of studies have been reported using this. Cellular in vitro endpoints for PL usually include fluorescent phospholipid accumulation in 2D cultured cells or changes in gene expression [26]. For the more in-depth investigation for PL, we conducted multiple examinations of the cellular changes in both systems to analyze the onset of PL, including cell viability, albumin secretion, morphology, protein immunostaining, ultra-microstructure analysis by transmission electron microscopy, and gene expression analysis. The results indicate that organoids better reflect metabolite-mediated hepatotoxicity in vivo and could be a valuable system for evaluating the phospholipidogenic effects of different compounds during drug development. 


\section{Results}

\subsection{Liver Cell Characterization}

The morphology of the 3D liver organoids and 2D HepG2 cells were compared as shown in Figure 1. Organoids cultured using an expansion medium (EM) appear as transparent spheres that have expanded in size. When organoids undergo differentiation, however, they show a compact and darkened appearance, and each cell adopts a hexagonal shape. HepG2 cells, on the other hand, grow as a monolayer and have a flattened appearance.

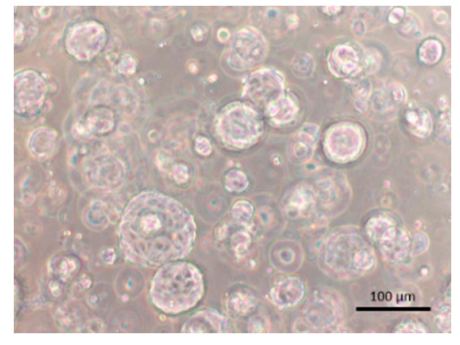

(a)

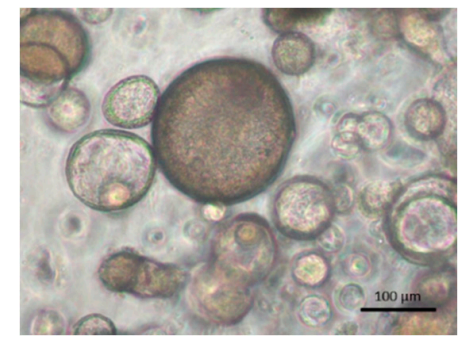

(b)

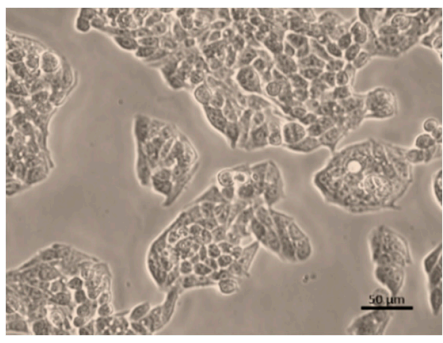

(c)

Figure 1. Morphology of cultured hepatocyte systems. (a) Three-dimensional human liver organoids on day 21 in expansion medium (EM); (b) 3D human liver organoids on day 9 in differentiation medium (DM); (c) HepG2 cells grown in monolayer culture. Original magnifications, $\times 100(\mathbf{a}, \mathbf{b})$ and $\times 200$ (c). Bar indicates $100 \mu \mathrm{m}(\mathbf{a}, \mathbf{b})$ and $50 \mu \mathrm{m}(\mathbf{c})$.

\subsubsection{Hepatic Marker Expression}

CYP3A4 and albumin gene expression was analyzed by quantitative real-time PCR (qPCR). RNA extracted from human liver tissue was used as a positive control. The mRNA expression level of CYP3A4 in organoids was marginally higher than that in HepG2 cells (Figure 2a). The mRNA expression level of albumin was comparable, however, between the organoids and HepG2 cells (Figure 2b). The mRNA expression levels of CYP3A4 and albumin significantly higher in liver tissues than in the organoid and HepG2 culture systems.

CYP3A4

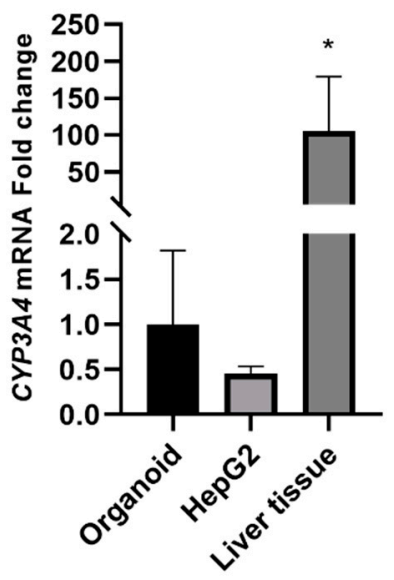

(a)

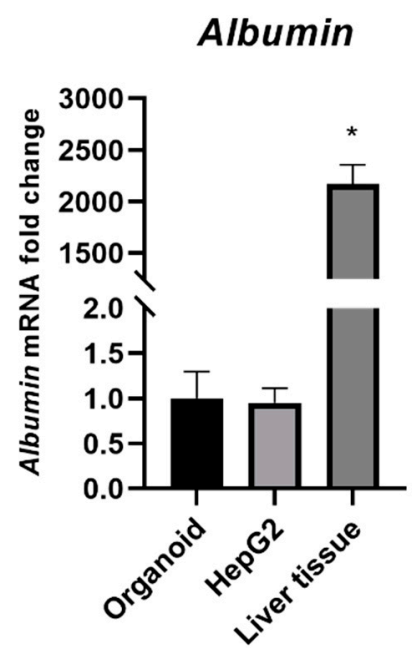

(b)

Figure 2. CYP3A4 and albumin mRNA expression in organoid and HepG2 cells. (a) 2-dCt values of CYP3A4; (b) 2-dCt values of albumin. Data are shown as a mean \pm standard error; ${ }^{*} p<0.05$. The experiments were performed in triplicate, each being repeated at least three times. 


\subsubsection{Glycogen Storage}

Glycogen accumulation in human liver organoids, HepG2 cells, and human liver tissue was evaluated by Periodic Acid Schiff (PAS) staining. The organoids showed clear positive glycogen accumulation through the appearance of strong magenta color staining. This staining in HepG2 cells was not as clear as much as organoids. The organoid cells contained polysaccharides or mucosubstances such as glycogen, glycoproteins, and glycolipids in their cytoplasm, as shown in Figure 3.

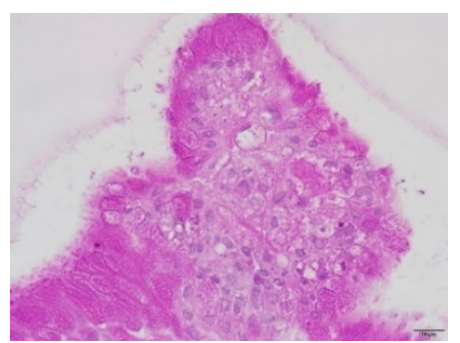

(a)

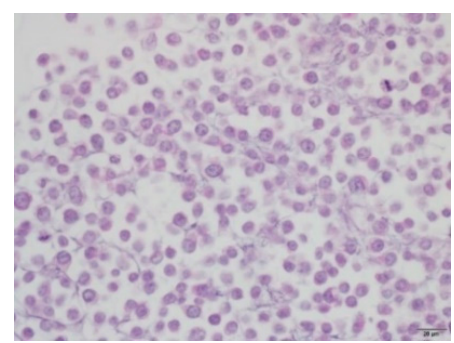

(b)

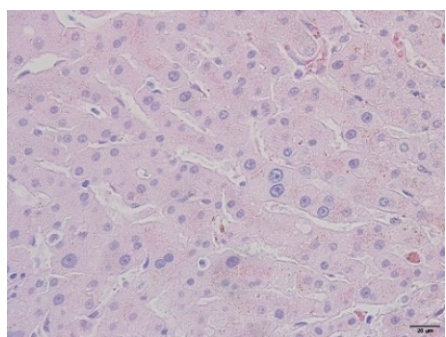

(c)

Figure 3. Glycogen accumulation in organoids and HepG2 cells. Polysaccharides or mucosubstances were stained positively with a magenta color. (a) DM day 12 organoids; (b) HepG2 cells; (c) Human liver tissue. Original magnification, $\times 400$. Bar indicates $20 \mu \mathrm{m}$.

\subsubsection{Hepatic Protein Expression}

The hepatic protein HNF4 $\alpha$ was detectable by immunofluorescence in both culture systems. As shown in Figure $4 a-c$, human liver organoids showed positive nuclear staining (green) for this protein which was stronger than that in the HepG2 cells. Non-specific positive staining was seen in the cytoplasm of HepG2 cells.

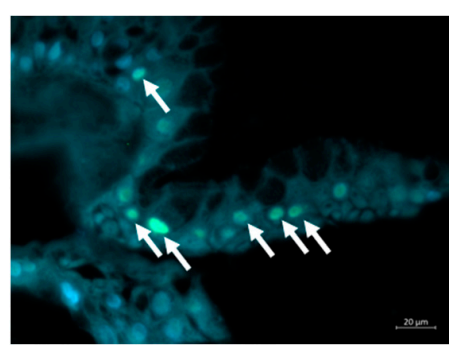

(a)

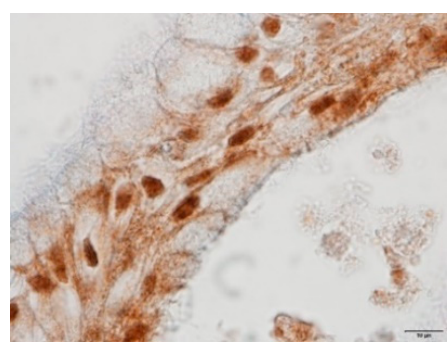

(d)

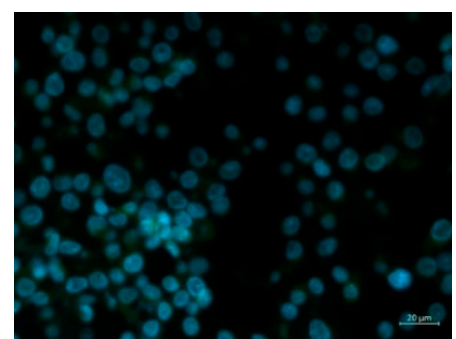

(b)

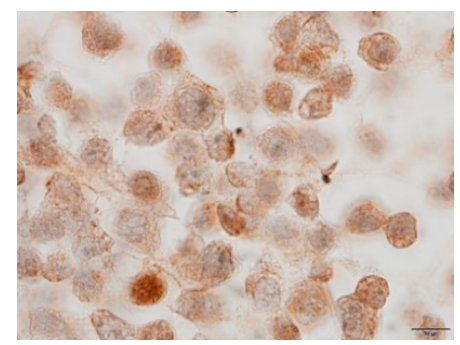

(e)

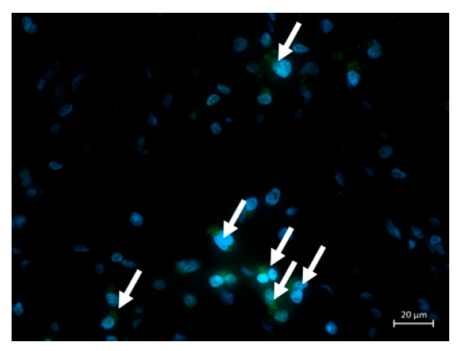

(c)

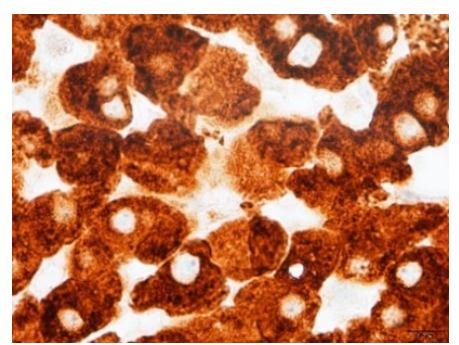

(f)

Figure 4. cont. 


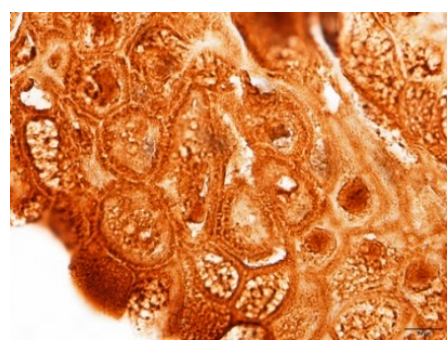

(g)

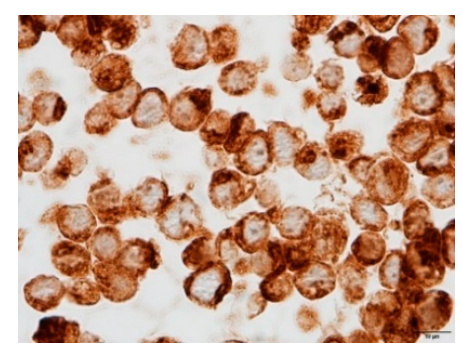

(h)

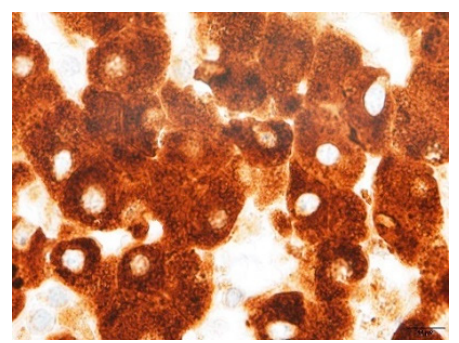

(i)

Figure 4. Immunostaining of HNF4 $\alpha(\mathbf{a}-\mathbf{c})$, CYP3A4 (d-f), and CYP1A2 (g-i). (a,d,g) DM day 12 organoids; (b,e,h) HepG2 cells; (c,f,i) Human liver tissue. Green florescent signals indicated positive staining for HNF4 $\alpha$ (white arrows). Brown color signals indicated positive staining for CYP3A4 or CYP1A2. Original magnifications, $\times 400(\mathbf{a}-\mathbf{c})$ and $\times 1000(\mathbf{d}-\mathbf{i})$. Bar indicates $20 \mu \mathrm{m}(\mathbf{a}-\mathbf{c})$, and $10 \mu \mathrm{m}(\mathbf{d}-\mathbf{i})$.

CYP3A4 and CYP1A2 expression were visualized by immunohistochemistry in both culture systems. As shown in Figure 4d-f, CYP3A4 expression in human liver organoids was more distinct than in HepG2 cells. CYP1A2 expression was clearly positive in both hepatocyte cultures (Figure 4g-i).

\subsection{Cell Viability Changes}

Three-dimensional human liver organoids were found to survive better when exposed to a high dose of a PL-inducing drug than HepG2 cells after $48 \mathrm{~h}$ of incubation. The viability of organoids and HepG2 cells changed drastically in every PL drug group. Both 2D and 3D cultured hepatocytes were killed by exposure to sertraline, a strong PL-inducing drug. Monolayers of HepG2 cells showed obvious cell death at a $20 \mu \mathrm{M}$ dose of amiodarone and sertraline, whilst the viability of the organoids was higher at these drug concentrations. Acetaminophen was used at $25 \mu \mathrm{M}$ or $50 \mu \mathrm{M}$ levels and caused no significant cell viability changes in either culture system. These cell viability data are shown in Figure 5.
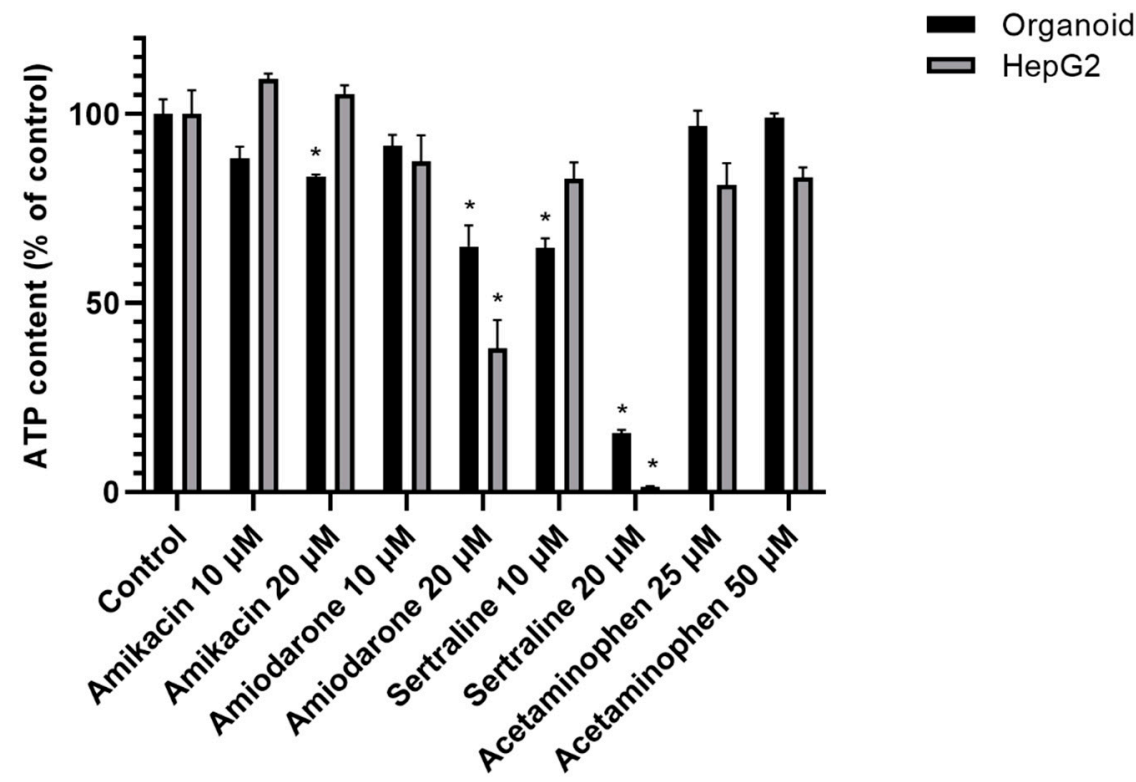

Figure 5. Cell viability changes in organoids and HepG2 cells. Human liver organoids and HepG2 cells were incubated with the indicated drugs (amikacin, amiodarone, sertraline, and acetaminophen) for $48 \mathrm{~h}$. A non-treatment group was used as a control (Con). Cell viability was assessed via the detection of ATP luminescence. Data are shown as a mean \pm standard error; ${ }^{*} p<0.05$. The experiments were performed in triplicate, each being repeated at least three times. 


\subsection{Albumin Secretion Content}

The albumin secretion level from HepG2 cells decreased more sharply than in liver organoids in the presence of a PL-inducing drug (depending on the intensity of its PL-inducing potential). Both hepatocyte culture systems were incubated with $10 \mu \mathrm{MPL}$-inducing drugs or $25 \mu \mathrm{M}$ acetaminophen as a negative control for $48 \mathrm{~h}$. The organoids maintained a more stable albumin secretion capacity than HepG2 cells as shown in Figure 6.

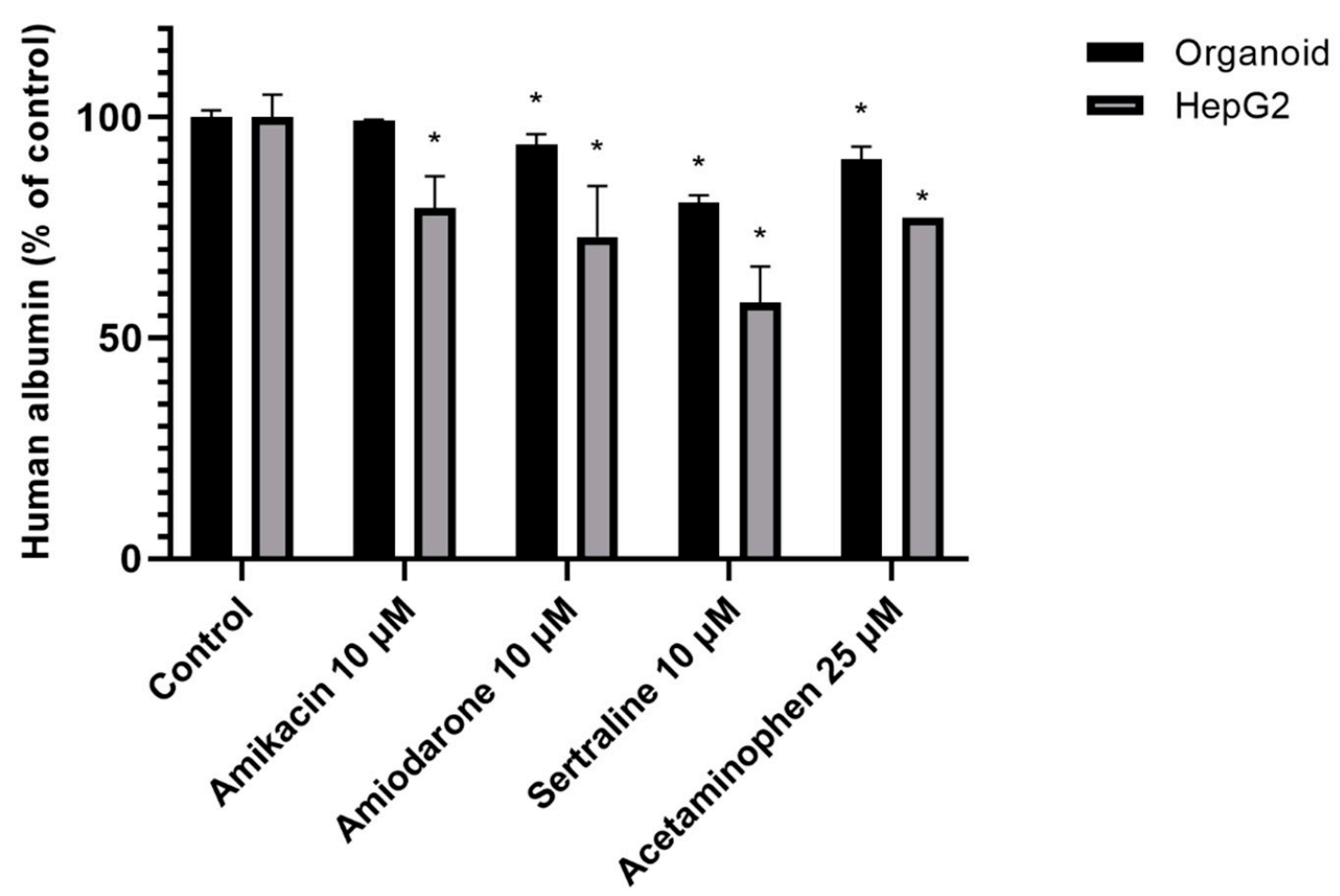

Figure 6. Secreted albumin levels from organoids and HepG2 cells. Organoids and HepG2 cells were incubated with the indicated drugs ( $10 \mu \mathrm{M}$ amikacin, amiodarone, sertraline, and $25 \mu \mathrm{M}$ acetaminophen) for $48 \mathrm{~h}$. A non-treatment group was used as a control. Data are shown as a mean \pm standard error; ${ }^{*} p<0.05$. The experiments were performed in duplicate, each being repeated at least three times.

\subsection{Evaluation of Drug-Induced Phospholipidosis}

\subsubsection{Morphological Changes}

To assess morphological changes in the organoid and HepG2 cell culture systems resulting from drug-induced $\mathrm{PL}$, the cells were treated with $10 \mu \mathrm{M}$ of the indicated drugs or $25 \mu \mathrm{M}$ acetaminophen for $48 \mathrm{~h}$, embedded in cell blocks, and stained with H\&E. As shown in Figure 7, drugs with a higher potency for PL induction caused higher cytoplasmic vacuole production in both culture systems. 


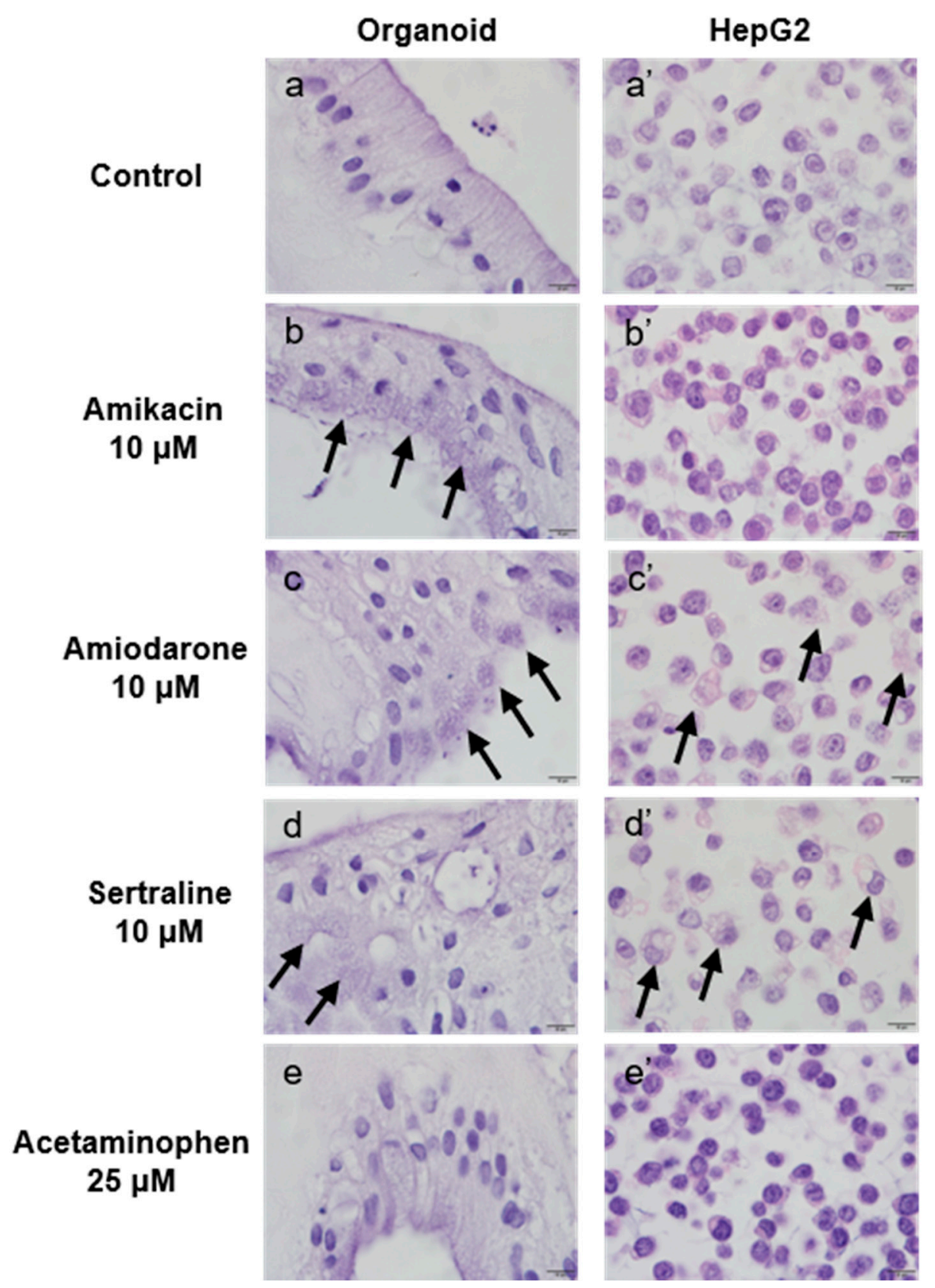

Figure 7. Microscopic evaluation of morphological changes in organoids and HepG2 cells following incubation with the indicated agents. Organoids (a-e) and HepG2 cells $\left(\mathbf{a}^{\prime}-\mathbf{e}^{\prime}\right)$ were treated with phospholipidosis (PL)-inducing drugs or untreated for $48 \mathrm{~h}$ as follows: Control (untreated) (a, $\left.\mathbf{a}^{\prime}\right), 10 \mu \mathrm{M}$ amikacin $\left(\mathbf{b}, \mathbf{b}^{\prime}\right), 10 \mu \mathrm{M}$ amiodarone (c, $\left.\mathbf{c}^{\prime}\right), 10 \mu \mathrm{M}$ sertraline $\left(\mathbf{d}, \mathbf{d}^{\prime}\right)$ and $25 \mu \mathrm{M}$ acetaminophen $\left(\mathbf{e}, \mathbf{e}^{\prime}\right)$. Arrows indicate PL-induced cytoplasmic vacuolation. Original magnification, $\times 1000$. Bar indicates $10 \mu \mathrm{m}$.

\subsubsection{Comparison of LAMP-2 Expression}

Phospholipid accumulation was detected by immunohistochemical staining for LAMP-2 (Figure 8). The cells were again incubated with $10 \mu \mathrm{M}$ of a PL-inducing drug (amikacin, amiodarone, or sertraline) or $25 \mu \mathrm{M}$ acetaminophen for $48 \mathrm{~h}$. The organoid cells had more apparent LAMP-2 positive staining in the cytoplasm compared with the HepG2 cells under the same conditions. Both kinds of cells in the sertraline-treated group showed the most strongly positive cytoplasmic staining. 


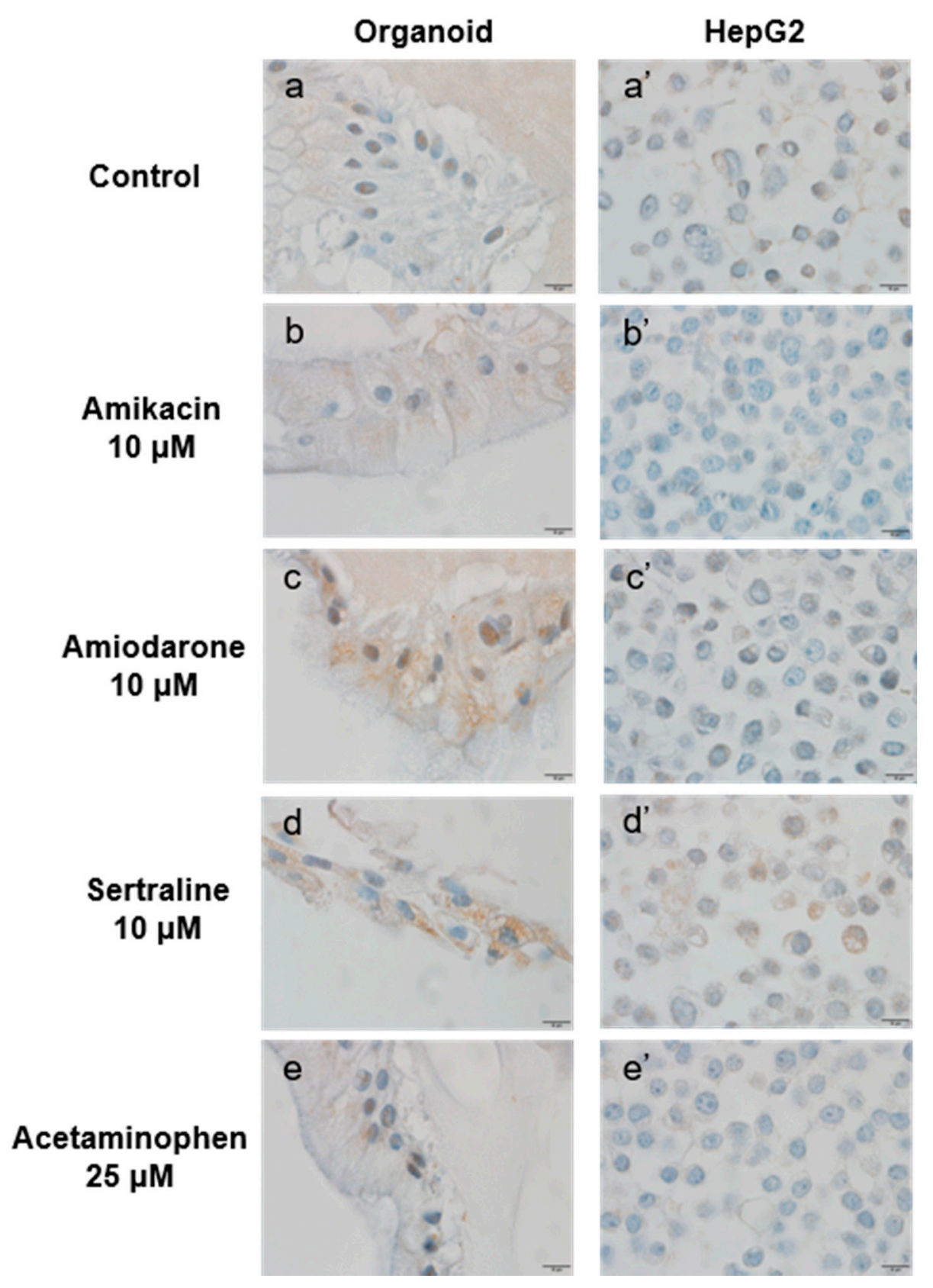

Figure 8. LAMP-2 expression in organoids and HepG2 cells following incubation with the indicated agents. Organoids (a-e) and HepG2 cells $\left(\mathbf{a}^{\prime}-\mathbf{e}^{\prime}\right)$ were treated with the indicated PL-inducing drugs or untreated for $48 \mathrm{~h}$ as follows: Control (untreated) (a, $\left.\mathbf{a}^{\prime}\right), 10 \mu \mathrm{M}$ amikacin $\left(\mathbf{b}, \mathbf{b}^{\prime}\right), 10 \mu \mathrm{M}$ amiodarone (c, $\left.\mathbf{c}^{\prime}\right)$, $10 \mu \mathrm{M}$ sertraline $\left(\mathbf{d}, \mathbf{d}^{\prime}\right)$, and $25 \mu \mathrm{M}$ acetaminophen (e,e $\left.\mathbf{e}^{\prime}\right)$. Brown signals indicate positive staining for LAMP-2. Original magnification, $\times 1000$. Bar indicates $10 \mu \mathrm{m}$.

\subsubsection{Confirmation of Drug-Induced Phospholipidosis}

Transmission electron microscopy was used to confirm drug-induced phospholipidosis in the liver organoids (Figure 9). The organoids treated with $10 \mu \mathrm{M}$ amiodarone for $48 \mathrm{~h}$ showed a clear production of lamellar bodies, which were not evident in the control group. Cell to cell junctions within the organoids and bile canaliculi were also observed. 


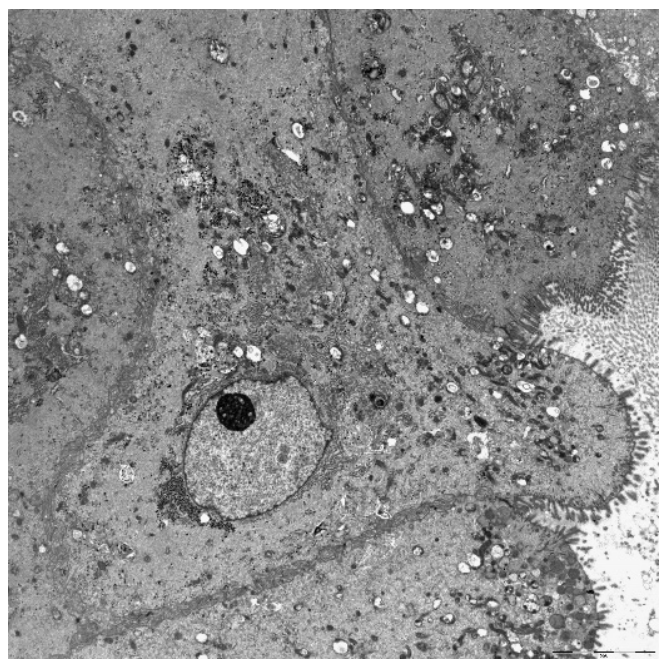

(a)

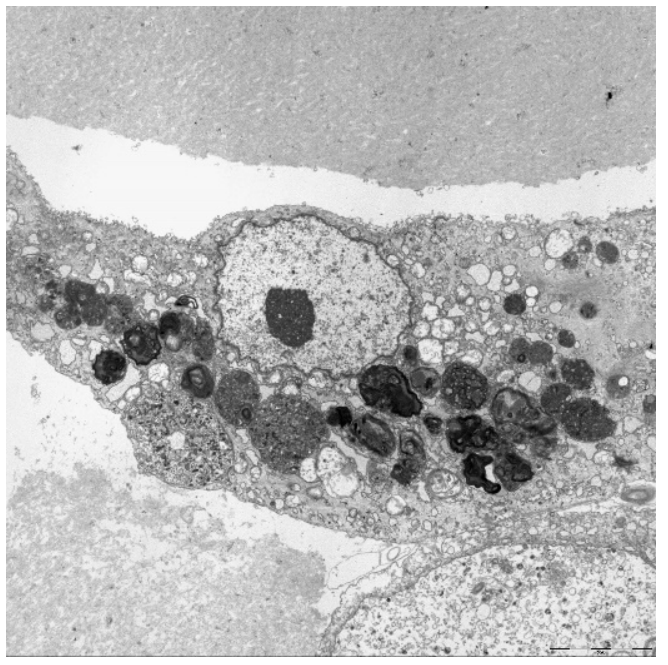

(b)

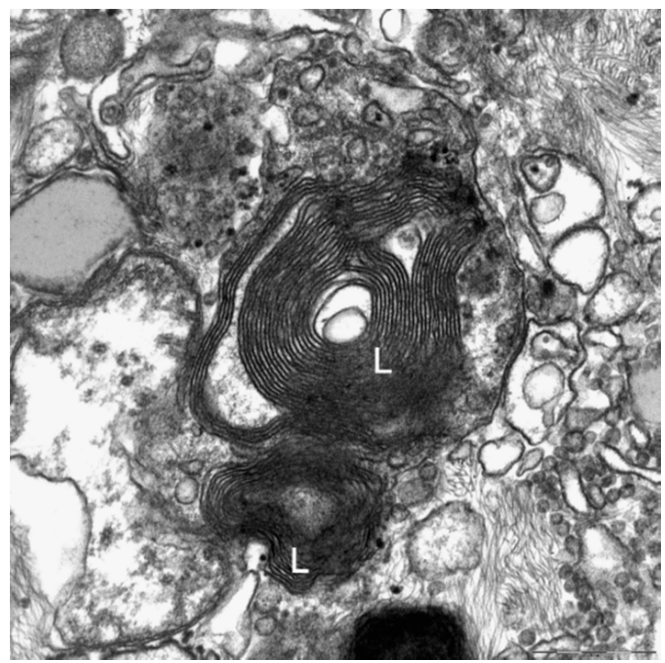

(c)

Figure 9. Transmission electron microscopic evaluation of the organoids, which had been differentiated for 12 days and then treated as follows: (a) Control (untreated); (b,c) $10 \mu \mathrm{M}$ amiodarone incubation for $48 \mathrm{~h}$. Lamellar bodies are indicated by ' $\mathrm{L}^{\prime}$. Original magnifications, $\times 3000(\mathbf{a}, \mathbf{b})$ and $\times 40,000$ (c).

\subsubsection{Gene Expression Changes under Conditions of Drug-Induced Phospholipidosis}

To evaluate the severity of drug-induced PL, the fold-change values for specific gene markers of this phenomenon were measured by qPCR. The cells in both culture systems were treated with amiodarone $(5 \mu \mathrm{M}, 10 \mu \mathrm{M})$ or sertraline $(5 \mu \mathrm{M}, 10 \mu \mathrm{M})$ for $48 \mathrm{~h}$. HepG2 cells were found to be extremely sensitive to $10 \mu \mathrm{M}$ sertraline toxicity and RNA extraction was therefore not possible under this condition. As indicated in Figure 10, the LSS and P8 mRNA expression levels of organoids showed an upregulation, as previously reported [36]. 


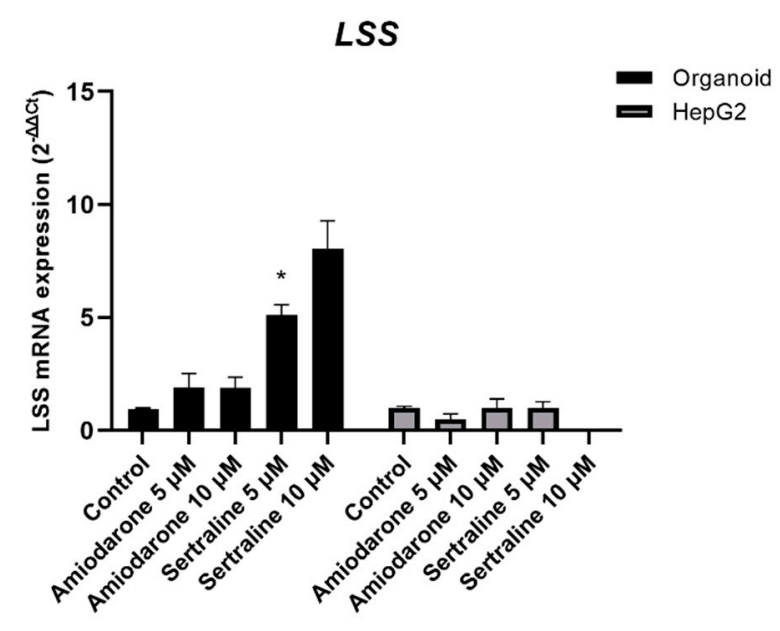

(a)

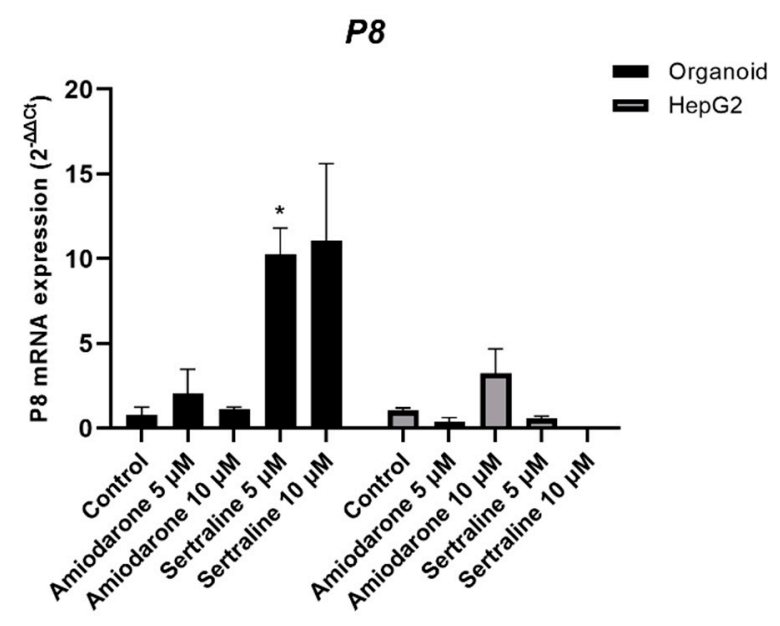

(b)

Figure 10. Fold changes in the gene markers of phospholipidosis in organoids and HepG2 cells. Fold changes were measured by the $2^{-\Delta \Delta C t}$ values of gene markers (a) LSS and (b) P8. mRNA fold changes are shown as a mean \pm standard error; ${ }^{*} p<0.05$. The experiments were performed in triplicate, each being repeated at least three times.

\section{Discussion}

PL induction by certain drugs is a potential problem for human pharmaceutical development. From a regulatory perspective, drug-induced PL also has several toxicological implications. When this phenomenon arises in lysosomes upon exposure to a drug concentration above $10 \mu \mathrm{M}$, it can result in a disruption to cellular membrane integrity and blockage of phospholipid degradation [3]. If this condition then continues throughout the prolonged administration of a particular drug, it may impact cellular function or even cause cell death [7]. Moreover, many other side effects are reported to be associated with drug-induced PL, such as cardiotoxicity (such as QT prolongation), myopathy, hepatotoxicity, nephrotoxicity, and pulmonary dysfunction [37].

Although PL is a frequent histological finding in exploratory preclinical in vivo studies, it is not certain that its occurrence in animals will be toxicologically relevant to humans. Differences in the 
phospholipase enzyme between humans and other animal species may be a plausible explanation for the poor predictive capacity of animal studies for this disorder [38]. Hence, it is desirable to identify drugs in their early developmental stages that have the potential to induce PL in humans [25]. Cell-based in vitro assays using various types of cells of human liver origin have been utilized in the past to screen for chemicals that provoke PL in humans. Significantly, we applied a robust 3D human liver organoid system to this purpose. We here describe the various examination of cellular alterations that occur during the onset of drug-induced PL in liver organoids, including viability changes, albumin secretion levels, morphological changes, and protein expression changes determined by immunostaining. We also confirmed that phospholipidosis is induced in organoids by detecting pathognomonic microstructural alterations through transmission electron microscopy. We further conducted the expression analysis of known PL marker genes.

Our detailed analyses of human liver organoids in this present study were conducted in parallel with the established HepG2 liver cell line that has been typically used for this type of screening $[28,29,34]$ in the past. Organoid cells that undergo differentiation show characteristics that are far more similar to primary hepatocytes than HepG2 immortalized liver carcinoma cells. The mRNA expression levels of CYP3A4 and albumin in both organoids and HepG2 cells were marginal compared with normal human liver tissue. However, the nuclear expression of $\mathrm{HNF} 4 \alpha$, a hepatic transcription factor, was far stronger in organoids, as determined by immunofluorescence. CYP3A4 and CYP1A2 expression were detectable in both cell cultures by immunohistochemistry. In PAS staining experiments, however, the organoids showed clear glycogen accumulation, whereas the HepG2 cells rarely stained positively.

The impacts of drug-induced PL on our 3D organoid and 2D hepatocyte culture systems were evaluated. As shown in Figure 5, the 3D human liver organoids survived in the presence of a high dose PL-inducing drug that was toxic to HepG2 cells at that same concentration over a 48-h incubation. The viability of HepG2 cells changed drastically in every PL drug group, and the number of HepG2 cells in the amikacin group actually showed a slight increase over the vehicle control group. Both 2D and 3D cultured hepatocytes were killed at a $20 \mu \mathrm{M}$ dose of amiodarone and sertraline, but the viability of organoids was higher than that of HepG2 cells. This survival change in HepG2 cells seems to be caused by the monolayer growth conditions that lead to a much wider exposure area to the drug. Additionally, since cells in vivo interact by forming close cellular junctions with surrounding cells, the lesser viability changes in organoids due to greater drug resistance are more likely to reflect an in vivo environment. It is significant in this regard also that the 3D liver organoids showed a more stable albumin secretion level than the HepG2 cell monolayers.

In our morphological evaluations of PL, the more potent PL-inducing drugs led to the production of more cytoplasmic microvesicular vacuoles in both the organoids and HepG2 cells. Although these foamy changes are presumed to be a result of drug-induced PL, these vacuolated entities caused by this condition resemble lipid accumulation or artifacts that can arise during the processing of a tissue slide for light microscopy. To clearly delineate that they were indeed the result of PL induction, we conducted an immunohistochemical analysis of LAMP-2, a specific marker of lysosome membranes that would clearly distinguish PL from lipid droplets. The expression of LAMP-2 was more evident in organoids than in HepG2 cells under the same PL-inducing conditions. To further confirm drug-induced PL in the organoids, differentiated organoids cultured with/without $10 \mu \mathrm{M}$ amiodarone for $48 \mathrm{~h}$ were examined under a transmission electron microscope. PL-distinctive lamellar bodies were observed only in the amiodarone-treated organoids. The observation of lamellar bodies in organoids following PL-inducing drug treatment may suggest that organoids are relatively sensitive to phospholipidosis. In addition, the ultra-microstructures of the organoids were found to include cell to cell junctions and bile canaliculi. The LSS and P8 mRNA levels were also found to be up-regulated in organoids as described previously $[35,36]$. Interestingly, the mRNA expression changes related to PL induction that were previously described [36] were not reproduced in HepG2 cells in our current experiments.

Our present study findings further revealed that 3D cultured human liver organoids are more sensitive to drug-induced PL and less affected by cytotoxicity than HepG2 cell monolayers. Since PL 
is a chronic cellular alteration, rather than cytotoxic acute toxicity, these results support the notion that 3D-structured liver organoids better reflect metabolite-mediated hepatotoxicity in vivo than a monolayer culture $[39,40]$. It has been reported in this regard that the detectable toxic concentration $(25 \mu \mathrm{M})$ of tetracycline in gel entrapped 3D cultured rat hepatocytes treated for $96 \mathrm{~h}$ is very close to the actual toxic serum concentration in rats $(27 \mu \mathrm{M})$ [41]. In contrast, and somewhat understandably, the HepG2 cells in our current experiments showed a clear decrease of viability and loss of liver function that does not correspond to the in vivo environment. Two-dimensional cultured HepG2 cells showed changes resulting from a greater drug dose under 2D in vitro culture conditions. The higher sensitivity of organoids to drug-induced PL further suggests that these structures are a far better match for the in vivo situation. Although we used organoids from a single patient in this study, if we could obtain the liver tissues and establish normal liver organoids from more people, the organoids will be able to be applied as a precise toxicity screening system that responds to PL-inducer according to the individual patient's characteristics.

It is difficult to predict drug-induced hepatotoxicity, especially chronic hepatotoxicity such as $\mathrm{PL}$, using in vitro systems because of the intrinsic limitations of cells grown outside of the body [42]. Organoids themselves are composed of a single type of cell from the liver so they are also an imperfect system for predicting likely drug responses in vivo. Moreover, the number of cells and the growth rate of each organoid are difficult to control. Co-culturing with other types of cells, such as immune cells [43] or endothelial cells [44], can make the microtissue more similar to in vivo environment, and many other studies are ongoing in this regard. The development of more reliable and appropriate cell systems for toxicity screening is thus still necessary for the early prediction of drug toxicity in vivo.

\section{Materials and Methods}

\subsection{Chemicals}

The PL-inducing agents and other compounds tested in the assays, including amikacin, amiodarone hydrochloride, sertraline hydrochloride, and acetaminophen, were purchased from Sigma-Aldrich (St. Louis, MO, USA). Information about each of these drugs can be found in prior reports [7,35]. Amikacin, amiodarone, and sertraline are weak, moderate and strong PL-inducing drugs, respectively. Acetaminophen was used as a negative control drug for the induction of PL. All other compounds and reagents used in the analyses were obtained at an analytical grade from common commercial sources.

\subsection{Cell Culture}

\subsubsection{Human Liver Organoids}

Human liver tissue $\left(0.5-1 \mathrm{~cm}^{3}\right)$ from a single patient was obtained from the hepatectomy performed at Asan Medical Center, Seoul, with informed consent given by the patient and approval by the Institutional Review Board of Asan Medical Center (Approval date: 20 July 2017, approval no. S2017-0969-0003). After surgical excision, the tissue was kept at $4{ }^{\circ} \mathrm{C}$ in Hanks' Balanced Salt Solution (HBSS) until processing. Human liver organoids were generated in accordance with the protocols of Broutier et al [30]. Briefly, the tissue was chopped with sterile scissors and digested by collagenase D (Roche) and DNase I (Sigma) in sterile Earle's Balanced Salt Solution (EBSS) medium (Thermo Fisher Scientific, Waltham, MA, USA). The isolated duct cells were then mixed with Matrigel (BD Biosciences, San Jose, CA, USA) or reduced growth factor BME 2 (Basement Membrane Extract, Type 2, Pathclear) (Amsbio, Abingdon, UK), and 5000-10,000 cells were seeded per well in a 24-well plate. After the matrigel or BME had been solidified, $500 \mu \mathrm{L}$ of culture medium was added per well. The expansion medium (EM) for the organoids was based on advanced DMEM/F12 (Invitrogen, Waltham, MA, USA) and various supplements were included. For the first 3 days, the medium was supplemented with $25 \mathrm{ng} / \mathrm{mL}$ recombinant human noggin (Peprotech, Rocky Hill, NJ, USA), $100 \mathrm{ng} / \mathrm{mL}$ Wnt3a (Peprotech), and $10 \mu \mathrm{M}$ Y27632 (Sigma Aldrich) to isolate the duct cells. The medium was 
then replaced with EM without noggin, Wnt3a, or Y27632. After a single duct cell had budded to an organoid, passaging was performed at a 1:2-1:4 split ratio once every 5-7 days. For normalization of the number of cells in each well, the organoids were dissociated into single cells using TrypleLE (Gibco, Waltham, MA, USA) and seeded with the same number per well. The cells were then cultured at $37^{\circ} \mathrm{C}$ in a humidified atmosphere containing $5 \% \mathrm{CO}_{2}$.

To differentiate organoids derived from hepatic progenitor cells in hepatocytes, the seeded organoids were maintained in culture for 5 days in EM supplemented with BMP7 $(25 \mathrm{ng} / \mathrm{mL})$ which was then replaced with differentiation medium (DM). The DM was advanced DMEM/F12 medium supplemented with 1\% N2 and 1\% B27 and containing $50 \mathrm{ng} / \mathrm{mL}$ recombinant human EGF, $10 \mathrm{nM}$ gastrin (Sigma), $25 \mathrm{ng} / \mathrm{mL}$ recombinant human HGF, $100 \mathrm{ng} / \mathrm{mL}$ recombinant human FGF19 (R and D, Minneapolis, MN, USA), 500 nM A83-01, (10 $\mu$ M DAPT (Sigma)), 25 ng/mL recombinant human BMP7 (Peprotech) and $30 \mu \mathrm{M}$ dexamethasone (Sigma). Fresh DM was added every 2-3 days for a period of 10-12 days.

\subsubsection{HepG2 Cells}

The human hepatocellular carcinoma cell line HepG2 was kindly provided by Dr. In Kyong Shim from the Asan Institute for Life Sciences (Seoul, Republic of Korea). These cells were cultured in DMEM supplemented with $10 \%$ fetal bovine serum (FBS), $100 \mathrm{U} / \mathrm{mL}$ penicillin and $100 \mathrm{~g} / \mathrm{mL}$ streptomycin in $175 \mathrm{~T}$ culture flasks. The cultures were maintained in a humidified atmosphere with $5 \% \mathrm{CO}_{2}$ at $37^{\circ} \mathrm{C}$ and subcultured every 3 or 4 days using $0.05 \%$ trypsin/EDTA in PBS.

\subsection{Treatment of Cells}

The 2D and 3D cultured cells were incubated in media supplemented with the chemical compound of interest for $48 \mathrm{~h}$. For subculturing, dissociated human liver organoid cells were seeded at 10,000 cells per well in 24 well plates. Differentiation was induced for 10 days when the diameter of the organoids did not exceed $200 \mu \mathrm{m}$ to avoid apoptosis. On day 10 of differentiation, the compounds being tested (5 or $10 \mu \mathrm{M}$ for amikacin, amiodarone, and sertraline; 25 or $50 \mu \mathrm{M}$ for acetaminophen) were added to the DM in separate experiments. HepG2 cells were seeded onto the culture plates at a suitable density for each assay. After the cells had adhered to the plates following an overnight incubation, the culture media was replaced and supplemented with each chemical.

\section{4. $R T-q P C R$}

As hepatic functional markers, the mRNA expression of CYP3A4 and albumin in the organoids and HepG2 cells were compared by quantitative real-time PCR (qPCR). Cells were harvested by Trizol and stored at $-80{ }^{\circ} \mathrm{C}$ until RNA extraction using chloroform as described previously [45]. The concentration and purity of the total RNA preparations were determined by measuring the absorbance at 260 and $280 \mathrm{~nm}$ with a NanoDrop (Thermo Fischer Scientific). To synthesize cDNA, reverse transcription (RT) was performed using the RevertAid First Strand cDNA Synthesis kit (Thermo Fisher Scientific). Briefly, $1000 \mathrm{ng}$ of total RNA was reacted in a $20 \mu \mathrm{L}$ mixture including oligo-dT oligonucleotide primer, RevertAid reverse transcriptase, and RiboLock RNase inhibitor. For CYP3A4, the forward oligo was 5'-CTTCATCCAATGGACTGCATAAAT-3', and the reverse oligo was $5^{\prime}$-TCCCAAGTATAACACTCTACACAGACAA-3'. For albumin, the forward oligo was $5^{\prime}$-ATGCCCCGGAACTCCTTTTC-3', and the reverse oligo was 5'-CAACAGGCAGGCAGCTTTAT-3' qPCR was performed using the ABI PRISM 7900HT Sequence Detection System (Thermo Fischer Scientific) with the following amplification protocol: $2 \mathrm{~min}$ at $50{ }^{\circ} \mathrm{C}$ and $2 \mathrm{~min}$ at $95^{\circ} \mathrm{C}$, followed by 40 cycles of denaturation for $15 \mathrm{~s}$ at $95^{\circ} \mathrm{C}$, and annealing and elongation for $1 \mathrm{~min}$ at $60^{\circ} \mathrm{C}$ in a final volume of $10 \mu \mathrm{L}$. The relative gene expression levels in the two culture systems were normalized to that of glyceraldehyde-3-phosphate dehydrogenase (GAPDH) and calculated using the comparative Ct method. 
To confirm the drug-induced PL in mRNA gene expression, the fold changes of several gene markers (LSS and P8) following drug-induced PL were measured by qPCR. LSS is associated with lipid metabolism/cholesterol biosynthesis and $P 8$ is concerned with cell cycle, proliferation, and death. Those genes were selected according to the previous report about a toxicogenomic approach to drug-induced PL analysis [36]. Amiodarone $(5,10 \mu \mathrm{M})$ and sertraline $(5,10 \mu \mathrm{M})$ were used to treat the cells for $48 \mathrm{~h}$. The cells were then collected, and their RNA was extracted with Trizol. After checking the concentration and purity of the total RNA, cDNA synthesis and qPCR were conducted as indicated above. Relative gene expression levels were normalized to a housekeeping gene, and the results were calculated by $2^{-\Delta \Delta C t}$ and compared with a vehicle control.

\subsection{PAS Staining}

Non-drug treated HepG2 cells and differentiated human organoids were fixed with $10 \%$ neutral buffered formalin for $30 \mathrm{~min}$. After washing the cells twice with phosphate-buffered saline (PBS), they were collected into a $1.5 \mathrm{~mL}$ tube and gently centrifuged to preserve the cellular structure. The resulting cell pellets were then embedded in Histogel. The solidified gel blocks containing the cells were transferred to tissue cassettes and tissue paraffin-embedded blocks were created using a standard method. Formalin-fixed human liver tissue was made to a paraffin-embedded block. To determine the glycogen storage levels in organoids HepG2, and human liver tissue, $3 \mu \mathrm{m}$-sectioned slides were treated with Periodic Acid Schiff (PAS) which positively stains glycogen, neutral mucins, some epithelial mucins, and the basement membranes of fungal walls (magenta color).

\subsection{Immunostaining (Immunofluorescence and Immunohistochemistry)}

The protein encoded by the HNF4A gene is a nuclear transcription factor that binds DNA and regulates several hepatic genes. Immunofluorescence was used to identify whether this liver-related protein was expressed in the organoids or HepG2 cultures. Briefly, $3 \mu \mathrm{m}$-sectioned paraffin-embedded cell slides were deparaffinized and antigen retrieval was performed by exposure to citrate buffer at $95^{\circ} \mathrm{C}$ for $15 \mathrm{~min}$. A primary anti-HNF $4 \alpha$ antibody (Abcam, Cambridge, UK) was incubated with the slide for $2 \mathrm{~h}$ at a $1 \mu \mathrm{g} / \mathrm{mL}$ concentration at room temperature. Alexa Fluor ${ }^{\mathrm{TM}} 488$ goat anti-mouse IgG (Invitrogen) was then incubated with the sample at a 1:1000 dilution for $1 \mathrm{~h}$ at room temperature. DAPI was used for nuclear counterstaining. Images were acquired under a fluorescent microscope (Observer.Z1, ZEISS, Oberkochen, Germany).

For identifying CYP3A4 and CYP1A2 expression, Immunohistochemistry was conducted. Paraffin-embedded cell blocks were sectioned and stained automatically using a Discovery XT Autostainer (Ventana Medical Systems, Oro Valley, AZ, USA). All reagents used for this automated immunohistochemistry were sourced from Ventana Medical Systems. The primary anti-CYP3A4 antibody (Abcam) and anti-CYP1A2 antibody (Abcam) were used at 1:500 dilution for $36 \mathrm{~min}$. The target antigen was visualized via a DAB reaction. Images were captured under a light microscope (BX53, Olympus, Tokyo, Japan).

\subsection{Histological Examination}

To investigate the morphological changes caused by the PL-inducing drug treatments, the cells were incubated with $10 \mu \mathrm{M}$ amikacin, amiodarone, and sertraline and $25 \mu \mathrm{M}$ acetaminophen for $48 \mathrm{~h}$. Cell block slides ( $3 \mu \mathrm{m}$-sections) were then prepared in the same way described formerly. After hematoxylin and eosin staining was conducted, the morphological features of the HepG2 cells and adult liver organoids were thereby evaluated.

\subsection{Detection of Lysosome-Associated Membrane Protein 2 (LAMP-2)}

To differentiate PL from other changes in the liver, immunostaining for LAMP-2 was conducted as previously described [46]. LAMP-2 is a promising marker for PL which has been characterized by immunohistochemistry in rat tissues treated with PL-inducing drugs [47], or cells treated with 
chloroquine [48]. Briefly, both hepatocyte culture systems were incubated with $10 \mu \mathrm{M}$ amikacin, amiodarone, sertraline and $25 \mu \mathrm{M}$ acetaminophen for $48 \mathrm{~h}$. Paraffin-embedded cell blocks were subsequently made, and each was sectioned and stained automatically using a Discovery XT Autostainer (Ventana Medical Systems). A primary anti-LAMP-2 antibody (Invitrogen) was used at a 1:200 dilution for $40 \mathrm{~min}$. The target antigen was visualized via a DAB reaction as described previously.

\subsection{Cell Viability Assay}

Organoids and HepG2 cells were incubated with 10 and $20 \mu \mathrm{M}$ of amikacin, amiodarone, and sertraline. Acetaminophen was added to both cell culture systems at 25 and $50 \mu \mathrm{M}$ concentrations. The ATP content in the cells was determined using the ATPlite luminescence ATP detection assay system (Perkin Elmer, Waltham, MA, USA). Briefly, cells were treated with $100 \mu \mathrm{L}$ of cell lysis solution for $5 \mathrm{~min}$ followed by the addition of substrate reagent for $5 \mathrm{~min}$ at room temperature. After adaptation in the dark for $10 \mathrm{~min}$, measurements were taken with a luminometer (VICTOR X2, Perkin Elmer). Data are presented as relative percentages to the control value, without drug exposure.

\subsection{Albumin Content Measurement}

Cultured media from the HepG2 cells and human liver organoids were collected before and at $48 \mathrm{~h}$ after chemical treatment. The cells were incubated with $10 \mu \mathrm{M}$ amikacin, amiodarone, sertraline, and $25 \mu \mathrm{M}$ acetaminophen. The albumin content secreted into the culture medium was assayed using a human albumin ELISA kit (Abcam) in accordance with the manufacturer's instructions. Data were reported as \% value from the control that the cells no PL-inducer was treated.

\subsection{Identification of Lamellar Bodies}

The liver organoids were treated with $10 \mu \mathrm{M}$ amiodarone for $48 \mathrm{~h}$ during differentiation days 10-12. Differentiated organoids with no treatment were used as controls. The cells were then fixed in $2.5 \%$ glutaraldehyde solution and stored at $4{ }^{\circ} \mathrm{C}$ for embedding and ultrathin sectioning. The fixed samples were then treated with a 1:1 $(v / v)$ mixture of quetol and dry ethanol for $30 \mathrm{~min}$, followed by two treatments in quetol for 30 and $120 \mathrm{~min}$, respectively. The samples were next mounted on the tips of Beem capsules, which were dried overnight in an oven at $74{ }^{\circ} \mathrm{C}$. The dried samples were sectioned on a microtome and stained with uranyl acetate for $20 \mathrm{~min}$. The samples were counterstained with palladium for a further $4 \mathrm{~min}$, and specimens were viewed under a transmission electron microscope (JEM-1200EX, JEOL, Tokyo, Japan).

\subsection{Statistical Analysis}

All data values are shown as a mean \pm SE. Statistical significance was determined by one-way ANOVA test in combination with Student's t-test with GraphPad Prism 6 (GraphPad Software Inc., La Jolla, CA, USA). $p$-values of less than 0.05 were considered statistically significant.

\section{Conclusions}

Our findings indicate the feasibility of organoids to predict and screen out the phospholipidosis. The drug-induced PL observed in humans can be successfully reproduced in primary human hepatocytes in 3D cultures and not just in traditional monolayer cultures. Unsurprisingly, human 3D liver organoids better reflect the properties of the primary human liver than hepatocellular carcinoma cell monolayer cultures. The unique cell structure of organoids may make them more resistant to drug-induced toxicity. Three-dimensional human liver organoids thus appear to be a useful and relevant system for evaluating the phospholipidogenic effects of different compounds. As a cell-based approach, 3D human liver organoids can, therefore, be used early in the drug development process to identify chemical agents with the potential to induce PL. 
Author Contributions: Conceptualization, W.-C.S. and J.-Y.L.; Data curation, J.-Y.L., H.-J.H., S.-J.L., E.-H.C. and H.-B.L.; Formal analysis, J.-Y.L. and S.-J.L.; Investigation, J.-Y.L., H.-J.H., S.-J.L., E.-H.C., H.-B.L., J.-H.S., H.S.L.; Supervision, W.-C.S., Writing of the original draft J.-Y.L. All authors have read and agreed to the published version of the manuscript.

Funding: This study was supported by the Technology Innovation Program, establishment of risk management platform with aim of reduce attrition of new drugs and its service [grant number: 10067737, 2016], funded by the Ministry of Trade, Industry \& Energy in Republic of Korea.

Conflicts of Interest: The authors declare no conflict of interest.

\section{Abbreviations}

$3 \mathrm{D}$

three-dimensional

2D two-dimensional

PL phospholipidosis

HBSS Hanks' Balanced Salt Solution

EBSS Earle's Balanced Salt Solution

BME 2 Basement Membrane Extract

EM expansion medium

DM differentiation medium

FBS fetal bovine serum

PBS phosphate-buffered saline

LAMP-2 lysosome-associated membrane protein 2

qPCR quantitative real-time polymerase chain reaction

RT reverse transcription

GAPDH glyceraldehyde-3-phosphate dehydrogenase

PAS Periodic Acid Schiff

\section{References}

1. Asaoka, Y.; Togashi, Y.; Imura, N.; Sai, T.; Miyoshi, T.; Miyamoto, Y. Immunohistochemistry of LAMP-2 and adipophilin for phospholipidosis in liver and kidney in ketoconazole-treated mice. Exp. Toxicol. Pathol. 2013, 65, 817-823. [CrossRef]

2. Gräbner, R. Influence of cationic amphiphilic drugs on the phosphatidylcholine hydrolysis by phospholipase A2. Biochem. Pharmacol. 1987, 36, 1063-1067. [CrossRef]

3. Halliwell, W.H. Cationic Amphiphilic Drug-Induced Phospholipidosis. Toxicol. Pathol. 1997, 25, 53-60. [CrossRef] [PubMed]

4. Reasor, M.J.; Kacew, S. Drug-induced phospholipidosis: Are there functional consequences? Exp. Biol. Med. 2001, 226, 825-830. [CrossRef] [PubMed]

5. Kaufmann, A.M.; Krise, J. Lysosomal Sequestration of Amine-Containing Drugs: Analysis and Therapeutic Implications. J. Pharm. Sci. 2007, 96, 729-746. [CrossRef]

6. Lenz, B.; Braendli-Baiocco, A.; Engelhardt, J.; Fant, P.; Fischer, H.; Francke, S.; Fukuda, R.; Groters, S.; Harada, T.; Harleman, H.; et al. Characterizing Adversity of Lysosomal Accumulation in Nonclinical Toxicity Studies: Results from the 5th ESTP International Expert Workshop; SAGE Publications Sage CA: Los Angeles, CA, USA, 2018.

7. Reasor, M.J.; Hastings, K.L.; Ulrich, R.G. Drug-induced phospholipidosis: Issues and future directions. Expert Opin. Drug Saf. 2006, 5, 567-583. [CrossRef] [PubMed]

8. Laurent, G.; Kishore, B.; Tulkens, P.M. Aminoglycoside-induced renal phospholipidosis and nephrotoxicity. Biochem. Pharmacol. 1990, 40, 2383-2392. [CrossRef]

9. Terry, R.D.; Weiss, M. Studies in Tay-Sachs disease. II. Ultrastructure of the cerebrum. J. Neuropathol. Exp. Neurol. 1963, 22, 18-55. [CrossRef] [PubMed]

10. Lazarus, S.S.; Vethamany, V.G.; Schneck, L.; Volk, B.W. Fine structure and histochemistry of peripheral blood cells in Niemann-Pick disease. Lab. Investig. 1967, 17, 155-170.

11. Rigas, B.; E Rosenfeld, L.; Barwick, K.W.; Enriquez, R.; Helzberg, J.; Batsford, W.P.; E Josephson, M.; Riely, C.A. Amiodarone hepatotoxicity: A clinicopathologic study of five patients. Ann. Intern. Med. 1986, 104, 348-351. [CrossRef] 
12. Shepherd, N.A.; Dawson, A.M.; Crocker, P.R.; Levison, D.A. Granular cells as a marker of early amiodarone hepatotoxicity: A pathological and analytical study. J. Clin. Pathol. 1987, 40, 418-423. [CrossRef] [PubMed]

13. Sun, H.; Xia, M.; Shahane, S.A.; Jadhav, A.; Austin, C.P.; Huang, R. Are hERG channel blockers also phospholipidosis inducers? Bioorg. Med. Chem. Lett. 2013, 23, 4587-4590. [CrossRef] [PubMed]

14. Slavov, S.; Stoyanova-Slavova, I.; Li, S.; Zhao, J.; Huang, R.; Beger, R.D.; Xia, M. Why are most phospholipidosis inducers also hERG blockers? Arch. Toxicol. 2017, 91, 3885-3895. [CrossRef] [PubMed]

15. Kacew, S.; Bergeron, M.G. Pathogenic factors in aminoglycoside-induced nephrotoxicity. Toxicol. Lett. 1990, 51, 241-259. [CrossRef]

16. Mingeot-Leclercq, M.-P.; Tulkens, P.M. Aminoglycosides: Nephrotoxicity. Antimicrob. Agents Chemother. 1999, 43, 1003-1012. [CrossRef]

17. Al-Shammari, B.; Khalifa, M.; Bakheet, S.A.; Yasser, M. A Mechanistic Study on the Amiodarone-Induced Pulmonary Toxicity. Oxidative Med. Cell. Longev. 2016, 2016, 6265853. [CrossRef]

18. Martin, W.J.; Standing, J.E. Amiodarone pulmonary toxicity: Biochemical evidence for a cellular phospholipidosis in the bronchoalveolar lavage of human subjects. J. Pharmacol. Exp. Ther. 1988, 244, 774-779.

19. D'Amico, D.J.; Kenyon, K.R.; Ruskin, J.N. Amiodarone keratopathy: Drug-induced lipid storage disease. Arch. Ophthalmol. 1981, 99, 257-261. [CrossRef]

20. Jacobs, J.M.; Costa-Jussà, F.R. The pathology of amiodarone neurotoxicity: II. Peripheral neuropathy in man. Brain 1985, 108, 753-769. [CrossRef]

21. Rappersberger, K.; Hönigsmann, H.; Ortel, B.; Tanew, A.; Konrad, K.; Wolff, K. Photosensitivity and Hyperpigmentation in Amiodarone-Treated Patients: Incidence, Time Course, and Recovery. J. Investig. Dermatol. 1989, 93, 201-209. [CrossRef]

22. Pirovino, M.; Müller, O.; Zysset, T.; Honegger, U. Amiodarone-induced hepatic phospholipidosis: Correlation of morphological and biochemical findings in an animal model. Hepatology 1988, 8, 591-598. [CrossRef] [PubMed]

23. Saito, K.; Maekawa, K.; Ishikawa, M.; Senoo, Y.; Urata, M.; Murayama, M.; Nakatsu, N.; Yamada, H.; Saito, Y. Glucosylceramide and Lysophosphatidylcholines as Potential Blood Biomarkers for Drug-Induced Hepatic Phospholipidosis. Toxicol. Sci. 2014, 141, 377-386. [CrossRef] [PubMed]

24. Lecommandeur, E.; Baker, D.; Cox, T.M.; Nicholls, A.W.; Griffin, J.L. Alterations in endo-lysosomal function induce similar hepatic lipid profiles in rodent models of drug-induced phospholipidosis and Sandhoff disease. J. Lipid Res. 2017, 58, 1306-1314. [CrossRef] [PubMed]

25. Chatman, L.A.; Morton, D.; Johnson, T.O.; Anway, S.D. A Strategy for Risk Management of Drug-Induced Phospholipidosis. Toxicol. Pathol. 2009, 37, 997-1005. [CrossRef]

26. Lecureux, L.; Cheng, C.S.; Herbst, J.; Reilly, T.P.; Lehman-McKeeman, L.; Otieno, M. Evaluation and validation of multiple cell lines and primary mouse macrophages to predict phospholipidosis potential. Toxicol. In Vitro 2011, 25, 1934-1943. [CrossRef]

27. Bhandari, N.; Figueroa, D.J.; Lawrence, J.W.; Gerhold, D.L. Phospholipidosis Assay in HepG2 Cells and Rat or Rhesus Hepatocytes Using Phospholipid Probe NBD-PE. Assay Drug Dev. Technol. 2008, 6, 407-419. [CrossRef]

28. Shahane, S.A.; Huang, R.; Gerhold, D.; Baxa, U.; Austin, C.P.; Xia, M. Detection of phospholipidosis induction: A cell-based assay in high-throughput and high-content format. J. Biomol. Screen. 2013, 19, 66-76. [CrossRef] [PubMed]

29. Van De Water, F.; Havinga, J.; Ravesloot, W.; Horbach, G.; Schoonen, W. High content screening analysis of phospholipidosis: Validation of a 96-well assay with CHO-K1 and HepG2 cells for the prediction of in vivo based phospholipidosis. Toxicol. In Vitro 2011, 25, 1870-1882. [CrossRef]

30. Broutier, L.; Andersson-Rolf, A.; Hindley, C.J.; Boj, S.F.; Clevers, H.; Koo, B.-K.; Huch, M. Culture and establishment of self-renewing human and mouse adult liver and pancreas 3D organoids and their genetic manipulation. Nat. Protoc. 2016, 11, 1724-1743. [CrossRef]

31. Xu, H.; Jiao, Y.; Qin, S.; Zhao, W.; Chu, Q.; Wu, K. Organoid technology in disease modelling, drug development, personalized treatment and regeneration medicine. Exp. Hematol. 2018, 7, 1-12. [CrossRef]

32. Meng, Q. Three-dimensional culture of hepatocytes for prediction of drug-induced hepatotoxicity. Expert Opin. Drug Metab. Toxicol. 2010, 6, 733-746. [CrossRef] [PubMed] 
33. Kostadinova, R.; Boess, F.; Applegate, D.; Suter, L.; Weiser, T.; Singer, T.; Naughton, B.; Roth, A. A long-term three dimensional liver co-culture system for improved prediction of clinically relevant drug-induced hepatotoxicity. Toxicol. Appl. Pharmacol. 2013, 268, 1-16. [CrossRef] [PubMed]

34. Donato, M.T.; Gomez-Lechon, M.J. Drug-induced liver steatosis and phospholipidosis: Cell-based assays for early screening of drug candidates. Curr. Drug Metab. 2012, 13, 1160-1173. [CrossRef] [PubMed]

35. Nioi, P.; Perry, B.K.; Wang, E.-J.; Gu, Y.-Z.; Snyder, R.D. In Vitro Detection of Drug-Induced Phospholipidosis Using Gene Expression and Fluorescent Phospholipid Based Methodologies. Toxicol. Sci. 2007, 99, 162-173. [CrossRef]

36. Sawada, H.; Takami, K.; Asahi, S. A Toxicogenomic Approach to Drug-Induced Phospholipidosis: Analysis of Its Induction Mechanism and Establishment of a Novel in Vitro Screening System. Toxicol. Sci. 2004, 83, 282-292. [CrossRef]

37. Tengstrand, E.A.; Miwa, G.T.; Hsieh, F.Y. Bis (monoacylglycerol) phosphate as a non-invasive biomarker to monitor the onset and time-course of phospholipidosis with drug-induced toxicities. Expert Opin. Drug Metab. Toxicol. 2010, 6, 555-570. [CrossRef]

38. Nonoyama, T.; Fukuda, R. Drug-induced Phospholipidosis -Pathological Aspects and Its Prediction. J. Toxicol. Pathol. 2008, 21, 9-24. [CrossRef]

39. Shen, C.; Shen, C.; Zhang, G.; Hu, W. Rifampicin exacerbates isoniazid-induced toxicity in human but not in rat hepatocytes in tissue-like cultures. Br. J. Pharmacol. 2007, 153, 784-791. [CrossRef]

40. Shen, C.; Zhang, G.; Qiu, H.; Shen, C. Acetaminophen-induced hepatotoxicity of gel entrapped rat hepatocytes in hollow fibers. Chem. Interact. 2006, 162, 53-61. [CrossRef]

41. Kikkawa, R.; Fujikawa, M.; Yamamoto, T.; Hamada, Y.; Yamada, H.; Horii, I. In vivo hepatotoxicity study of rats in comparison with in vitro hepatotoxicity screening system. J. Toxicol. Sci. 2006, 31, 23-34. [CrossRef]

42. O'brien, P.J.; Chan, K.; Silber, P.M. Human and animal hepatocytes in vitro with extrapolation in vivo. Chem. Interact. 2004, 150, 97-114. [CrossRef] [PubMed]

43. Neal, J.; Li, X.; Zhu, J.; Giangarra, V.; Grzeskowiak, C.L.; Ju, J.; Liu, I.H.; Chiou, S.-H.; Salahudeen, A.A.; Smith, A.R.; et al. Organoid Modeling of the Tumor Immune Microenvironment. Cell 2018, 175, 1972-1988. [CrossRef] [PubMed]

44. Pettinato, G.; Lehoux, S.; Ramanathan, R.; Salem, M.M.; He, L.-X.; Muse, O.; Flaumenhaft, R.; Thompson, M.T.; Rouse, E.A.; Cummings, R.D.; et al. Generation of fully functional hepatocyte-like organoids from human induced pluripotent stem cells mixed with Endothelial Cells. Sci. Rep. 2019, 9, 8920. [CrossRef] [PubMed]

45. Farrell, R.E. Chapter 2-RNA Isolation Strategies. In RNA Methodologies, 4th ed.; Farrell, R.E., Ed.; Academic Press: San Diego, CA, USA, 2010; pp. 45-80. [CrossRef]

46. Ma, J.Y.; Snook, S.; Garrovillo, S.; Johnson, C.; La, D. An Immunohistochemical Investigation of Renal Phospholipidosis and Toxicity in Rats. Int. J. Toxicol. 2017, 36, 386-394. [CrossRef]

47. Obert, L.; Sobocinski, G.P.; Bobrowski, W.F.; Metz, A.L.; Rolsma, M.D.; Altrogge, D.M.; Dunstan, R.W. An Immunohistochemical Approach to Differentiate Hepatic Lipidosis from Hepatic Phospholipidosis in Rats. Toxicol. Pathol. 2007, 35, 728-734. [CrossRef]

48. Chen, P.M.; Gombart, Z.J.; Chen, J.W. Chloroquine treatment of ARPE-19 cells leads to lysosome dilation and intracellular lipid accumulation: Possible implications of lysosomal dysfunction in macular degeneration. Cell Biosci. 2011, 1, 10. [CrossRef]

(C) 2020 by the authors. Licensee MDPI, Basel, Switzerland. This article is an open access article distributed under the terms and conditions of the Creative Commons Attribution (CC BY) license (http://creativecommons.org/licenses/by/4.0/). 